\title{
Arsenic doped $p$-type zinc oxide films grown by radio frequency magnetron sputtering
}

\author{
J. C. Fan, ${ }^{1}$ C. Y. Zhu, ${ }^{1}$ S. Fung, ${ }^{1}$ Y. C. Zhong, ${ }^{2}$ K. S. Wong ${ }^{2}$ Z. Xie, ${ }^{3}$ G. Brauer ${ }^{4}$ \\ W. Anwand ${ }^{4,5}$ W. Skorupa, ${ }^{4}$ C. K. To, ${ }^{1}$ B. Yang, ${ }^{1}$ C. D. Beling, ${ }^{1}$ and C. C. Ling ${ }^{1, a}$ \\ ${ }_{1}^{1}$ Department of Physics, The University of Hong Kong, Pokfulam Road, Hong Kong, \\ People's Republic of China \\ ${ }^{2}$ Department of Physics, Hong Kong University of Science and Technology, Clear Water Bay, \\ Hong Kong, People's Republic of China \\ ${ }^{3}$ College of Physics and Microelectronic Science, Hunan University, Changsha 410082, \\ People's Republic of China \\ ${ }^{4}$ Institut für Ionenstrahlphysik und Materialforschung, Forschungszentrum Dresden-Rossendorf, \\ Postfach 510119, D-01314 Dresden, Germany \\ ${ }^{5}$ Institut für Strahlenphysik, Forschungszentrum Dresden-Rossendorf, \\ Postfach 510119, D-01314 Dresden, Germany
}

(Received 6 August 2009; accepted 30 August 2009; published online 9 October 2009)

\begin{abstract}
As-doped $\mathrm{ZnO}$ films were grown by the radio frequency magnetron sputtering method. As the substrate temperature during growth was raised above $\sim 400{ }^{\circ} \mathrm{C}$, the films changed from $n$ type to $p$ type. Hole concentration and mobility of $\sim 6 \times 10^{17} \mathrm{~cm}^{-3}$ and $\sim 6 \mathrm{~cm}^{2} \mathrm{~V}^{-1} \mathrm{~s}^{-1}$ were achieved. The $\mathrm{ZnO}$ films were studied by secondary ion mass spectroscopy, $\mathrm{x}$-ray photoelectron spectroscopy (XPS), low temperature photoluminescence (PL), and positron annihilation spectroscopy (PAS). The results were consistent with the $\mathrm{As}_{\mathrm{Zn}}-2 \mathrm{~V}_{\mathrm{Zn}}$ shallow acceptor model proposed by Limpijumnong $e t$ al. [Phys. Rev. Lett. 92, 155504 (2004)]. The results of the XPS, PL, PAS, and thermal studies lead us to suggest a comprehensive picture of the As-related shallow acceptor formation. (C) 2009 American Institute of Physics. [doi:10.1063/1.3236578]
\end{abstract}

\section{INTRODUCTION}

$\mathrm{ZnO}$ is a wide band gap semiconductor attracting much attention due to its potential in optoelectronic and spintronic applications. ${ }^{1-4}$ To realize these applications, the technology for fabricating a $p-n$ junction is crucially important. Undoped $\mathrm{ZnO}$ material is $n$ type but reliable $p$-type doping of the material is difficult to accomplish. This asymmetric doping difficulty arises from the low solubility of dopants and the compensation of defects with low formation energies. ${ }^{5}$ After extensive efforts, successful $p$-type $\mathrm{ZnO}$ was achieved by doping with group $\mathrm{V}$ elements ${ }^{6-19}$ or by group III and V element codoping. ${ }^{20-22}$ In the case of As doping, $p$-type $\mathrm{ZnO}$ materials were fabricated by different methods, such as evaporation/sputtering process, ${ }^{14}$ ion implantation, ${ }^{16}$ pulsed laser deposition, ${ }^{17}$ thermal diffusion of As after depositing a $\mathrm{ZnO}$ film on GaAs substrate, ${ }^{18}$ and hybrid beam deposition. ${ }^{9}$ Group V atoms substituting at the $\mathrm{O}$ site and the $\mathrm{Zn}$ site of the $\mathrm{ZnO}$ lattice are acceptors and donors, respectively. $\mathrm{N}_{\mathrm{O}}$ was a shallow acceptor with $E_{a}=0.17-0.20 \mathrm{eV}{ }^{8}$ For the case of As (and similar to $\mathrm{Sb}$ ), first-principles calculations showed that $\mathrm{As}_{\mathrm{O}}$ was a deep acceptor $(\sim 1000 \mathrm{meV})$ having a high formation energy $(>6 \mathrm{eV}), \mathrm{As}_{\mathrm{Zn}}$ was a donor, and $\mathrm{As}_{i}$ was amphoteric. ${ }^{23}$ These As defects were thus not the shallow acceptor associating with the observed $p$-type conduction. Limpijumnong et al. ${ }^{23}$ proposed a model to explain the

\footnotetext{
${ }^{a)}$ Author to whom correspondence should be addressed. Electronic mail: ccling@hku.hk.
}

observed $p$-type conductivity in As-doped $\mathrm{ZnO}$. The energetically favorable reaction between the $\mathrm{Zn}$ vacancy and $\mathrm{As}_{\mathrm{Zn}}$ occurs as

$$
\mathrm{As}_{\mathrm{Zn}}^{3+}+\mathrm{V}_{\mathrm{Zn}}^{2-} \rightarrow\left(\mathrm{As}_{\mathrm{Zn}}-\mathrm{V}_{\mathrm{Zn}}\right)^{+}
$$

This is followed by another energetically favorable reaction:

$$
\left(\mathrm{As}_{\mathrm{Zn}}-\mathrm{V}_{\mathrm{Zn}}\right)^{+}+\mathrm{V}_{\mathrm{Zn}}^{2-} \rightarrow\left(\mathrm{As}_{\mathrm{Zn}}-2 \mathrm{~V}_{\mathrm{Zn}}\right)^{-} .
$$

The resulting $\mathrm{As}_{\mathrm{Zn}}-2 \mathrm{~V}_{\mathrm{Zn}}$ is a stable acceptor having states at $\varepsilon(0 /-)=0.15 \mathrm{eV}$ and $\varepsilon(-/ 3-)=1.37 \mathrm{eV}$. Monitoring the conversion electron emission channeling from radioactive ${ }^{73} \mathrm{As}$, Wahl et al. ${ }^{24}$ reported that the majority of the As atoms implanted in $\mathrm{ZnO}$ located in the substitutional $\mathrm{Zn}$ sites in agreement with the model of Limpijumnong et al. ${ }^{23}$ There were also x-ray photoelectron spectroscopy (XPS) studies resulting in a similar conclusion. ${ }^{17,18}$ Limpijumnong et al. ${ }^{25}$ pointed out that the $\mathrm{x}$-ray absorption near-edge structure data of As-doped $\mathrm{ZnO}$ measured by Vaithianathan et al. ${ }^{26}$ also supported the model. However, Vaithianathan et al. ${ }^{27}$ thought that there was some uncertainty in this claim.

In the present paper, we report the fabrication of Asdoped $p$-type $\mathrm{ZnO}$ films grown on silicon dioxide and glass using the radio frequency magnetron sputtering (RFMS) method. Conduction type and carrier concentration dependence on growth substrate temperature were investigated. The samples were characterized by secondary ion mass spectroscopy (SIMS), XPS, room temperature (RT) Hall measurement, photoluminescence (PL), and positron annihilation spectroscopy (PAS) aiming to understand the formation of the As-related shallow acceptor. 


\section{EXPERIMENTAL}

As-doped $\mathrm{ZnO}$ was grown on $\mathrm{SiO}_{2}$ by RFMS using a ceramic target containing $1 \mathrm{~mol} \% \mathrm{Zn}_{3} \mathrm{As}_{2}$ and $99 \mathrm{~mol} \%$ $\mathrm{ZnO} . \mathrm{SiO}_{2}$ layers of $250 \mathrm{~nm}$ thick were grown in dry oxygen on $\mathrm{Si}$ substrates. The base pressure of the growth chamber was $10^{-3} \mathrm{~Pa}$. Prior to the $\mathrm{ZnO}$ film growth, the targets were cleaned by $\operatorname{Ar}(99.99 \%)$ sputtering for $20 \mathrm{~min}$ at $0.5 \mathrm{~Pa}$. The radio frequency power was maintained constant at $120 \mathrm{~W}$ and the substrate temperature $\left(T_{S}\right)$ was varied from 200 to $500{ }^{\circ} \mathrm{C}$. The undoped $\mathrm{ZnO}$ film was deposited on the $\mathrm{SiO}_{2}$ substrate with a rf power of $120 \mathrm{~W}$ while the substrate was kept at $350^{\circ} \mathrm{C}$. As-doped $\mathrm{ZnO}$ films were also grown on glass substrates by the dual sputtering target method. The two sputtering targets used were $99.999 \% \mathrm{ZnO}$ and pure $\mathrm{Zn}_{3} \mathrm{As}_{2}$. The $\mathrm{ZnO}$ :As deposition was carried out with a rf power of $100 \mathrm{~W}$ on the $\mathrm{ZnO}$ target and a dc power of $2.5 \mathrm{~W}$ on the $\mathrm{Zn}_{3} \mathrm{As}_{2}$ target. The substrate temperatures were varied from 250 to $450{ }^{\circ} \mathrm{C}$.

XRD measurements were carried out with a Philips PW1825 x-ray diffractometer using the $\mathrm{Cu} K \alpha$ line $(\lambda$ $=0.15406 \mathrm{~nm}$ ). SIMS depth profiling of the samples were obtained by using $3 \mathrm{keV} \mathrm{O}_{2}{ }^{+}$as primary ions (Physical Electronics model 7200). The chemical states of As were studied by XPS using the $\mathrm{Mg} K \alpha$ line (Physical Electronics model 5600). The X-ray source and the $C 1 s$ line were taken as the standard reference. Hall measurements were carried out with the Accent HL5500 Hall system using van der Pauw configuration. Ohmic contacts for the Hall measurements were fabricated by thermal evaporation of $50 \mathrm{~nm} \mathrm{Al} \mathrm{film.} \mathrm{The} \mathrm{Ohmic}$ behavior of the contacts was ensured before each of the Hall measurements. PL measurements were performed with the $325 \mathrm{~nm} \mathrm{He}-\mathrm{Cd}$ laser line at $1 \mathrm{~mW}$, a SPEX 500M monochromator, and a charge coupled device detector. A RT annihilation spectroscopy study ${ }^{28,29}$ was carried out with a monoenergetic positron beam, while the positron energy was varied up to $20 \mathrm{keV}$. The annihilation gamma photon energy spectra were detected by a high purity Ge detector and the corresponding nuclear electronics, which have an energy resolution of $1.09 \mathrm{keV}$ at the $514 \mathrm{keV}$ gamma ray photopeak of Sr-85. Each of the energy spectra consisted of $10^{6}$ counts of annihilation events. The Doppler broadening of the annihilation gamma radiation was parametrized by the $S$ and the $W$ parameters, defined by the ratios of counts in the central region and the counts in the high-momentum regions symmetrical to the peak to the total annihilation events, respectively. Depth profiling of the sample was carried out by monitoring the $S$ parameter (and also the $W$ parameter) as a function of the positron incident energy $E$. The $S$ and $W$ parameters of the RFMS films were obtained by fitting the $S-E$ and the $W-E$ depth profiles using the source code VEPFIT, ${ }^{30}$ which considered the positron implantation, the subsequent positron diffusion, trapping into vacancy type defects and electron-positron annihilation.

\section{RESULTS AND DISCUSSIONS}

The presence of the As atoms in the As-doped $\mathrm{ZnO}$ films was confirmed by SIMS measurements. The SIMS depth profiles showed that the films had a thickness of $\sim 280 \mathrm{~nm}$

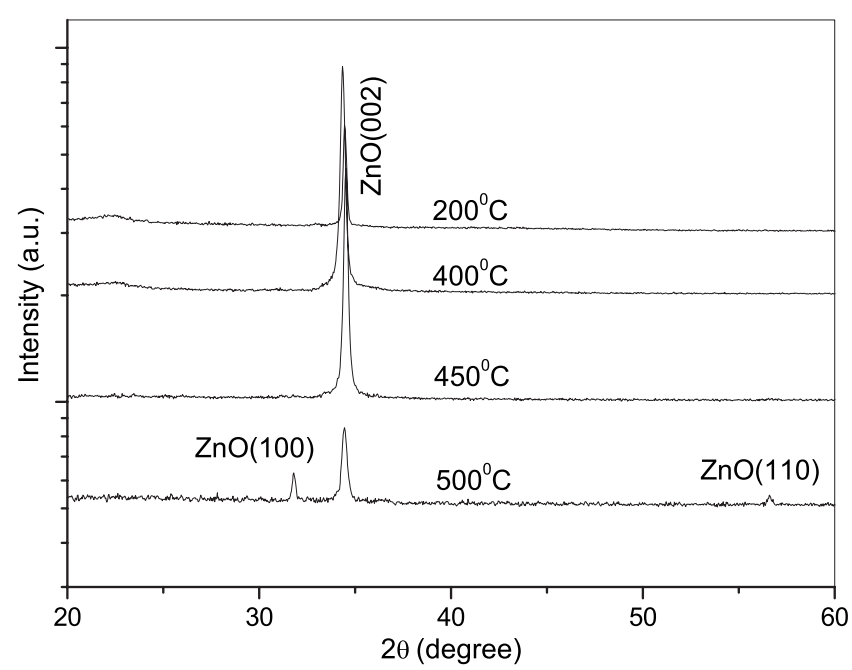

FIG. 1. XRD spectra of the RFMS grown As-doped $\mathrm{ZnO}$ films on $\mathrm{SiO}_{2}$ with different substrate temperatures.

and the As atoms were uniformly distributed. Calibrating with an As-implanted sample with known fluence, the As concentration within the film was estimated to be $\sim 10^{19}-10^{20} \mathrm{~cm}^{-3}$. The $\mathrm{Zn}$ to $\mathrm{O}$ atomic ratio was found to be 1.23 .

XRD spectra of the As-doped $\mathrm{ZnO}$ samples grown on $\mathrm{SiO}_{2}$ at $T_{S}=200,400,450$, and $500{ }^{\circ} \mathrm{C}$ had a peak at $2 \theta$ $=34.35^{\circ}-34.52^{\circ}$ [corresponding to the $\left.\mathrm{ZnO}(002)\right]$ and full width at half maximum $(\mathrm{FWHM})=0.19^{\circ}, 0.25^{\circ}, 0.23^{\circ}$, and $0.32^{\circ}$, respectively (shown in Fig. 1). For samples grown at $T_{S}<500{ }^{\circ} \mathrm{C}$, no other peak was observed. This indicates the single phase wurtzite structure and the $c$-axis preferred orientation of these fabricated $\mathrm{ZnO}$ films. However, for the sample grown at $T_{S}=500{ }^{\circ} \mathrm{C}$, small peaks corresponding to other orientations, $\mathrm{ZnO}$ (100) and $\mathrm{ZnO}$ (110), were observed in the XPS spectrum.

RT Hall measurements were performed on the undoped $\mathrm{ZnO}$ sample and the As-doped $\mathrm{ZnO}$ samples fabricated at different $T_{S}$. For each of the growing condition, average carrier concentration and mobility were obtained from at least eight different independent samples. The undoped $\mathrm{ZnO}$ film had $n=6 \times 10^{18} \mathrm{~cm}^{-3}$ and $\mu_{n}=17 \mathrm{~cm}^{2} \mathrm{~V} \mathrm{~s}^{-1}$. The carrier concentrations of the As-doped $\mathrm{ZnO}$ film grown on the $\mathrm{SiO}_{2}$ and the glass substrates as a function of $T_{S}$ were shown in Fig. 2. For the films grown on the $\mathrm{SiO}_{2}$ substrates, the Asdoped film grown at $200{ }^{\circ} \mathrm{C}$ was $n$ type $\left(n \sim 5 \times 10^{16} \mathrm{~cm}^{-3}\right.$ and $\left.\mu_{e} \sim 4 \mathrm{~cm}^{2} \mathrm{~V}^{-1} \mathrm{~s}^{-1}\right)$. For $T_{S}=350{ }^{\circ} \mathrm{C}$, the samples yielded varied from $n$ type to $p$ type as illustrated by the large error bar of the $T_{S}=350{ }^{\circ} \mathrm{C}$ data in Fig. 2. For $T_{S}$ $=400{ }^{\circ} \mathrm{C}$, the sample became $p$ type having $p=3$ $\times 10^{18} \mathrm{~cm}^{-3}$ and $\mu_{h}=1 \mathrm{~cm}^{2} \mathrm{~V}^{-1} \mathrm{~s}^{-1}$ though the error bar of the hole concentration was still large implying a large fluctuation of the hole concentrations measured from each samples. Further increasing $T_{S}$ would decreased the hole concentration, which reached values of $6 \times 10^{17} \mathrm{~cm}^{-3}\left(\mu_{h}\right.$ $\left.=6 \mathrm{~cm}^{2} \mathrm{~V}^{-1} \mathrm{~s}^{-1}\right)$ and $2 \times 10^{17} \mathrm{~cm}^{-3}\left(\mu_{h}=5 \mathrm{~cm}^{2} \mathrm{~V}^{-1} \mathrm{~s}^{-1}\right)$ at $T_{S}=450$ and $500{ }^{\circ} \mathrm{C}$, respectively. The sample grown at $T_{S}$ $=450{ }^{\circ} \mathrm{C}$ was the $p$-type film having the smallest error bar and the narrowest FWHM of the $\mathrm{ZnO}(002)$ peak among the XRD spectra (Fig. 1). This implied that As-doped $\mathrm{ZnO}$ film 


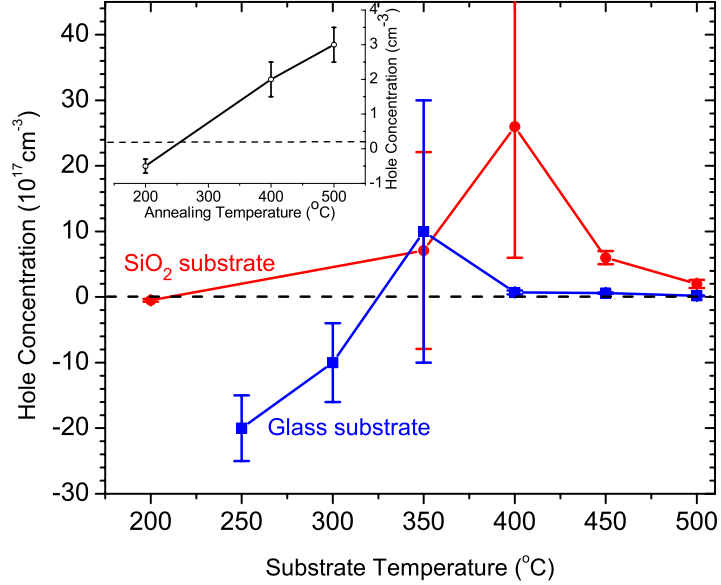

FIG. 2. (Color online) Hole concentration of the RFMS grown As-doped $\mathrm{ZnO}$ film plotted against growing substrate temperature. The red circles and the blue squares represented the films grown on $\mathrm{SiO}_{2}$ and glass substrates, respectively. The other growing parameters were fixed and were given in the text. The inset showed the annealing effect of the $n$-type As-doped $\mathrm{ZnO}$ sample grown on $\mathrm{SiO}_{2}$ at substrate temperature of $200{ }^{\circ} \mathrm{C}$.

grown on $\mathrm{SiO}_{2}$ at $T_{S}=450{ }^{\circ} \mathrm{C}$ had the best reproducibility and crystalline structure. The hole concentrations measured on this sample measured 6 months later did not show any significant change, while the sample was kept at controlled temperature and humidity of $\sim 20{ }^{\circ} \mathrm{C}$ and $50-60 \%$, respectively.

As-doped $\mathrm{ZnO}$ films grown on the glass substrates had very similar substrate temperature dependence compared to those grown on the $\mathrm{SiO}_{2}$ substrate. The $\mathrm{ZnO}$ :As films grown on glass at $T_{S}<350{ }^{\circ} \mathrm{C}$ were $n$ type (with $\mu_{e}$ $\sim 1 \mathrm{~cm}^{2} \mathrm{~V}^{-1} \mathrm{~s}^{-1}$ ). At $T_{S}=350{ }^{\circ} \mathrm{C}$, individual samples varied from $n$ type to $p$ type. At $T_{S}>350{ }^{\circ} \mathrm{C}$, stable $p$-type samples were obtained, though the hole concentrations of films grown on the glass substrate were smaller than those grown on the $\mathrm{SiO}_{2}$ substrate (Fig. 2).

In attempting to further understand the thermal induced $n$-to- $p$-type conversion of the $\mathrm{ZnO}$ :As samples, we have carried out Ar-atmosphere annealing study on the As-doped $n$-type sample grown on the glass substrate at $T_{S}=200{ }^{\circ} \mathrm{C}$ (results shown in the inset of Fig. 2). After the 400 and $500{ }^{\circ} \mathrm{C}$ annealing, the sample was converted from $n$ type to $p$ type having $p=2 \times 10^{16} \mathrm{~cm}^{-3}$.

It was noticed that stable $p$-type $\mathrm{ZnO}$ film was formed only with $T_{S}>400$ and $400{ }^{\circ} \mathrm{C}$ annealing in air could convert the $n$-type As-doped $\mathrm{ZnO}$ sample grown at $T_{S}=200{ }^{\circ} \mathrm{C}$ to $p$ type. This implied that thermal process was needed for the $p$-type film formation. One possible explanation was associated with the thermal activation onset of the diffusion of the defects (i.e., probably $\mathrm{V}_{\mathrm{Zn}}$ ) involved in the formation of the shallow acceptor complex $\mathrm{As}_{\mathrm{Zn}}-2 \mathrm{~V}_{\mathrm{Zn}}$, as shown in Eq. (1). Moreover, the increased resistivity in hydrothermally grown $\mathrm{ZnO}$ single crystal introduced by electron irradiation was recovered by $400{ }^{\circ} \mathrm{C}$ annealing in air. ${ }^{31}$ This was associated with the removal of the electron irradiation introduced compensating traps. This implied thermal process within this temperature range also had the effect of removing compensating centers, which was favorable for the $p$-type conduction.

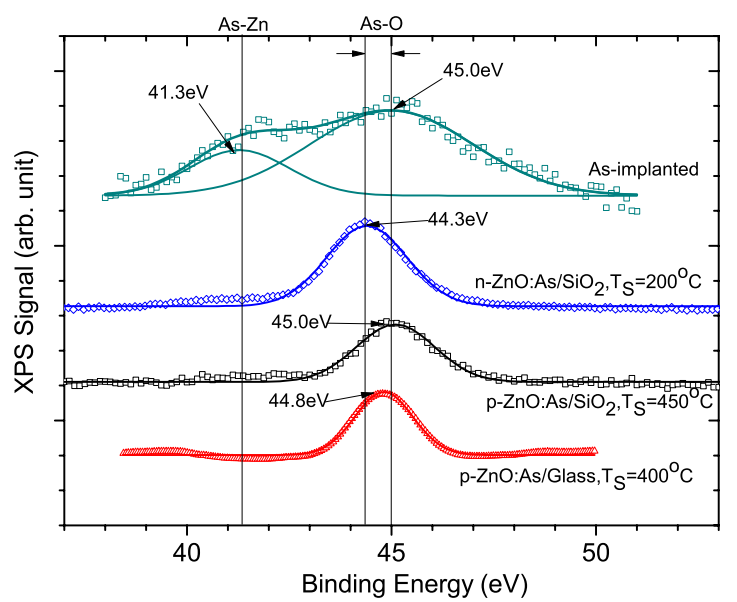

FIG. 3. (Color online) As (3d) XPS spectra of (a) as-Arsenic-implanted sample and As-doped $\mathrm{ZnO}$ films grown by RFMS (b) on $\mathrm{SiO}_{2}$ at substrate temperature of $200{ }^{\circ} \mathrm{C}$, (c) on $\mathrm{SiO}_{2}$ at substrate temperature of $450{ }^{\circ} \mathrm{C}$; and (d) on glass at substrate temperature of $450{ }^{\circ} \mathrm{C}$. The peaks at $\sim 41$ and $\sim 45 \mathrm{eV}$ originated from As-atom locating at the $\mathrm{O}$ site and the $\mathrm{Zn}$ site of the lattice, respectively.

XPS measurements were carried out on the As-doped samples grown at $T_{S}=200{ }^{\circ} \mathrm{C}\left(n \sim 10^{16} \mathrm{~cm}^{-3}\right)$ and $T_{S}$ $=450{ }^{\circ} \mathrm{C}\left(p \sim 10^{17} \mathrm{~cm}^{-3}\right)$ on $\mathrm{SiO}_{2}, T_{S}=400{ }^{\circ} \mathrm{C}$ on glass $(n$ $\sim 10^{16} \mathrm{~cm}^{-3}$ ) and on an As-implanted $\mathrm{ZnO}$ single crystal sample $^{32}$ for comparison. The As-implantation (energy $=100 \mathrm{keV}$ and fluence $=10^{15} \mathrm{~cm}^{-2}$ ) was carried out on an undoped melt grown $\mathrm{ZnO}$ single crystal $\left(n \sim 10^{16} \mathrm{~cm}^{-3}\right)$ manufactured by Cermet Inc. Post-implantation annealing of the As-implanted sample was carried out in air at 750, 900, and $1200{ }^{\circ} \mathrm{C}$. No $p$-type layer was formed in these Asimplanted samples. ${ }^{32}$ For the RFMS samples, XPS measurements were performed at a depth of $\sim 5 \mathrm{~nm}$ to eliminate any surface effect. For the As-implanted sample, it was performed at a depth of $\sim 50 \mathrm{~nm}$ corresponding to the depth of maximum As concentration (obtained by SIMS measurement). From Fig. 3, the As (3d) XPS spectra of the Asimplanted sample clearly show two peaks at $\sim 41$ and $\sim 45 \mathrm{eV}$. For all the RFMS grown films, the As $(3 d)$ XPS spectra were dominated by a single peak at $44.3-45.0 \mathrm{eV}$. The signal near the $\sim 41 \mathrm{eV}$ region was barely detectable. The $\sim 45 \mathrm{eV}$ peak was close to the reported binding energies of 44.7-45.1 eV for As-O bond. ${ }^{33,34}$ The lower binding energy peak $\sim 41.3 \mathrm{eV}$ observed only in the present Asimplanted sample was close to that of As binding with a non-oxygen atom such as As- $\mathrm{Zn}(\sim 41.4 \mathrm{eV}) .{ }^{33,34}$ The $\sim 45$ and the $\sim 41 \mathrm{eV}$ peak observed in the present study were thus attributed to As substituting the $\mathrm{Zn}$ and O, respectively, i.e., defects containing the microstructures of $\mathrm{As}_{\mathrm{Zn}}$ and $\mathrm{As}_{\mathrm{O}}$, respectively.

Regardless of the $T_{S}$ (hence also the conduction type), the As atom in the RFMS grown films predominantly existed in the form of $\mathrm{As}_{\mathrm{Zn}}$ or the relevant complex. The $\mathrm{As}_{\mathrm{O}}$ related defect was not formed presumably due to the high formation energy involved. ${ }^{23}$ For the As-implanted sample, however, an $\mathrm{As}_{\mathrm{O}}$ related XPS signal was observed (Fig. 3) despite its high formation energy. This was because ion implantation was not a thermodynamically equilibrium process. The existence of the $\mathrm{As}_{\mathrm{O}}$ defect, which was a deep donor, was probably the 


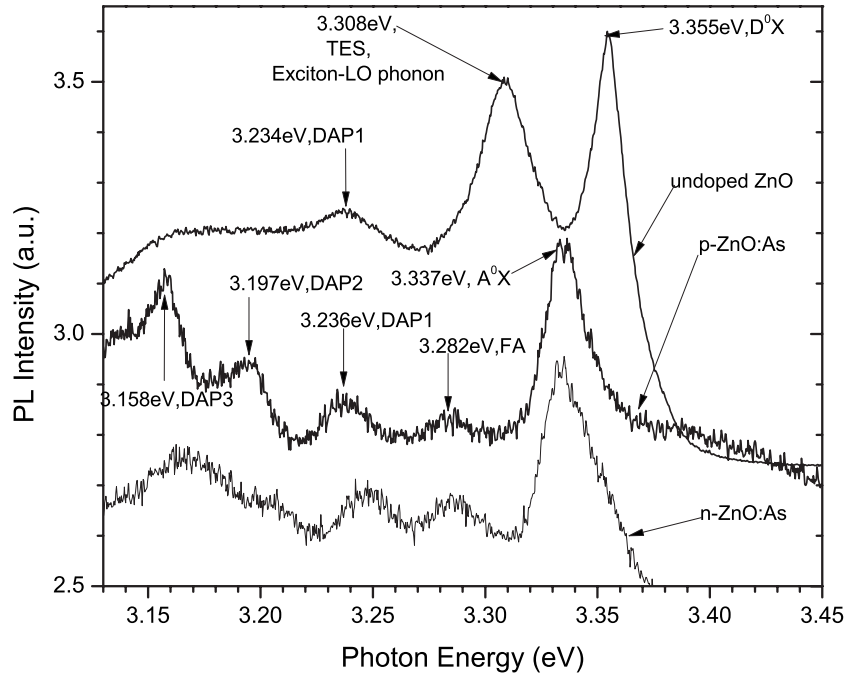

FIG. 4. NBE region of $10 \mathrm{~K}$ PL spectra for the undoped $n$-type $\mathrm{ZnO}$ sample, the $\mathrm{ZnO}$ :As sample grown at $T_{S}=450{ }^{\circ} \mathrm{C}$, and the $\mathrm{ZnO}$ :As sample grown at $T_{S}=200{ }^{\circ} \mathrm{C}$. The films were grown on the $\mathrm{SiO}_{2}$ substrate.

reason for the failure for obtaining $p$-type conduction in the As-implanted samples. The detection of $\mathrm{As}_{\mathrm{Zn}}$ related defects in the As-doped RFMS grown $\mathrm{ZnO}$ films was consistent with the As-related shallow acceptor model of Limpijumnong et al. ${ }^{23}$ in which all the three As-related defects involved in the acceptor formation reactions (1) and (2) (i.e., $\mathrm{As}_{\mathrm{Zn}}$, $A s_{Z n}-V_{Z n}$, and $A s_{Z n}-2 V_{Z n}$ ) contained the microstructure of $A s_{Z n}$. However, it would also be worth pointing out that the present XPS results could not offer unambiguous microstructures of the $\mathrm{As}_{\mathrm{Zn}}$-related defects in the RFMS samples as revealed by the $\sim 45 \mathrm{eV}$ peak. Thus we could not distinguish if the detected $\sim 45 \mathrm{eV}$ peak originated from the isolated $\mathrm{As}_{\mathrm{Zn}}$, the $\mathrm{As}_{\mathrm{Zn}}-\mathrm{V}_{\mathrm{Zn}}$ complex donor, the $\mathrm{As}_{\mathrm{Zn}}-2 \mathrm{~V}_{\mathrm{Zn}}$ complex acceptor, or other else containing the $\mathrm{As}_{\mathrm{Zn}}$.

The near band edge (NBE) part of the $10 \mathrm{~K}$ PL spectrum for the undoped sample had peaks at 3.355, 3.308, and 3.234 eV (Fig. 4). From the NBE region of the As-doped sample of the $10 \mathrm{~K} \mathrm{PL}$ spectrum (Fig. 4), five peaks at 3.337, 3.282, $3.236,3.197$, and $3.158 \mathrm{eV}$ were identified. Although the assignments of the PL peaks are not yet unambiguous, it is still instructive to discuss our results by referencing previous literatures. The 3.355 and $3.308 \mathrm{eV}$ peaks were only observed in the undoped sample. Similar lines were also observed by Petersen et al. ${ }^{35}(\sim 3.350$ and $3.303 \mathrm{eV})$ in $n$-type $\mathrm{ZnO}$ grown by sol-gel process and by Zhong et al. ${ }^{36}$ (3.357 and $3.309 \mathrm{eV}$ ) in $\mathrm{ZnO}$ tetrapod. The $\sim 3.36 \mathrm{eV}$ was ascribed to the $D^{0} X$. The $3.31 \mathrm{eV}$ line was associated with the corresponding two-electron-satellite (TES) and/or exciton-LO phonon emission. Look et al. ${ }^{37}$ pointed out that the neutraldonor-bound-exciton $\left(D^{0} X\right)$ line appeared at the $\sim 3.36 \mathrm{eV}$ region. The 3.355 and $3.308 \mathrm{eV}$ lines from the undoped $n$-type sample were thus assigned to be the $D_{0} X$ and the TES/exciton-LO phonon lines, respectively. The $3.234 \mathrm{eV}$ observed in the undoped sample and also the $3.236 \mathrm{eV}$ line in the As-doped sample were similar to the $\sim 3.24 \mathrm{eV}$ donoracceptor-pair (DAP) emission suggested by Peterson et al., ${ }^{35}$ and were thus assigned as DAP. The 3.337 and $3.282 \mathrm{eV}$ lines were only observed in the As-doped samples and were

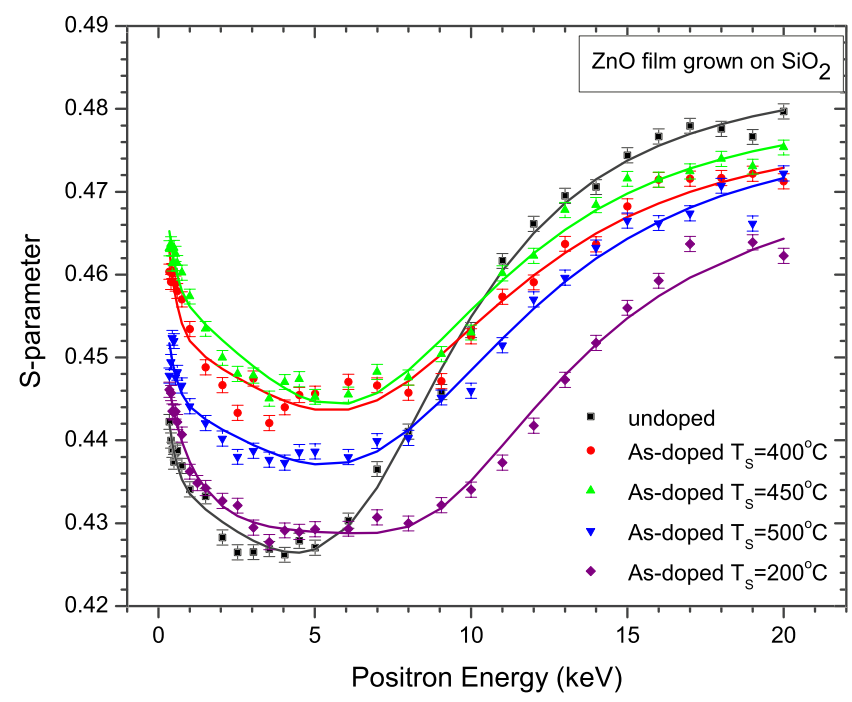

FIG. 5. (Color online) $S$ parameter against positron incident energy $E$ depth profiles for the undoped $\mathrm{ZnO}$ film grown at the substrate temperature of $350{ }^{\circ} \mathrm{C}$ and the As-doped $\mathrm{ZnO}$ films grown on the $\mathrm{SiO}_{2}$ substrate at different substrate temperatures. All the films were grown on the $\mathrm{SiO}_{2}$ substrates by the RFMS method. The line labeled as $290 \mathrm{~nm}$ was the positron energy which referred to the physical position of the $\mathrm{ZnO} / \mathrm{SiO}_{2}$ boundary.

thus associated with the acceptor-bound exciton $\left(A^{0} X\right)$ emission and the free electron to acceptor (FA) recombination, respectively. ${ }^{9,18,37}$ The other two peaks at 3.158 and $3.197 \mathrm{eV}$ from the $p$-type sample were attributed to the DAP emissions. The acceptor binding energy $E_{A}$ was calculated by $E_{A}=E_{g}-E_{\mathrm{FA}}+k T / 2$, where $E_{g}=3.437 \mathrm{eV}^{38}$ and $E_{\mathrm{FA}}=3.282 \mathrm{eV}$ were the band gap energy and the temperature dependent transition energy, respectively. This yielded a value of $E_{A}=155 \mathrm{meV}$ in good agreement with the $\varepsilon(0 /-)$ $=0.15 \mathrm{eV}$ of the $\mathrm{As}_{\mathrm{Zn}}\left(2 \mathrm{~V}_{\mathrm{Zn}}\right)$ acceptor of Limpijumnong et al. $^{23}$

It was also interesting to verify if the As-related shallow acceptor was formed in the $\mathrm{ZnO}$ :As film grown on $\mathrm{SiO}_{2}$ at $T_{S}=200{ }^{\circ} \mathrm{C}$ as the film was $n$-type conducting. The $10 \mathrm{~K} \mathrm{PL}$ spectrum of this sample was included in Fig. 4, which clearly indicated the two acceptor related peaks, namely, the $A^{0} X$ and the FA lines. This implied that the high resistance $n$-type nature of the As film grown at $T_{S}=200{ }^{\circ} \mathrm{C}$ was probably due to defect compensation.

PAS studies were conducted on the undoped sample, and the $\mathrm{ZnO}$ :As samples grown on $\mathrm{SiO}_{2}$ at different substrate temperatures. The measured $S$ and $W$ parameters are the weighted sum of the contribution at different annihilation sites, i.e., $S=\sum_{i} f_{i} S_{i}$, where $f_{i}$ and $S_{i}$ are the fraction and the characteristic $S$ parameter of the $i$ th annihilation state. ${ }^{28,29}$ Positrons implanted into the sample will be rapidly thermalized according to a Makhov implantation depth profile. ${ }^{28,29}$ The thermalized positrons undergo random walk diffusion and would be trapped by neutral or negatively charged vacancy type defects. The annihilation gamma photons originated from positron localized in the vacancy state would be less Doppler broadened (thus yielding a higher $S$ parameter and a lower $W$ parameter) relative to positron annihilating from the delocalized bulk state.

The $S$ - $E$ depth profiles of the undoped- $\mathrm{ZnO} / \mathrm{SiO}_{2}$ and the $\mathrm{ZnO}: \mathrm{As} / \mathrm{SiO}_{2}$ grown at different $T_{S}$ were shown in Fig. 5 
TABLE I. Tabulated $S$ parameter, $W$ parameter, effective positron diffusion length $L_{+}$and boundary position of the $\mathrm{ZnO}$ layer fitted from the $S-E$ and the $W$ - $E$ data for the $\mathrm{ZnO}$ films grown on the $\mathrm{SiO}_{2}$ substrate at different substrate temperatures.

\begin{tabular}{lcccc}
\hline \hline & & & & \\
& $S$ & $W$ & $\begin{array}{c}L_{+} \\
(\mathrm{nm})\end{array}$ & $\begin{array}{c}\text { Fitted boundary } \\
\text { of the } \\
\text { first layer } \\
(\mathrm{nm})\end{array}$ \\
\hline Undoped & $0.4268(3)$ & $0.09425(28)$ & $5(3)$ & $261(13)$ \\
As-doped $T_{S}=200{ }^{\circ} \mathrm{C}$ & $0.4306(3)$ & $0.09268(27)$ & $9(2)$ & $465(11)$ \\
As-doped $T_{S}=350{ }^{\circ} \mathrm{C}$ & $0.4416(3)$ & $0.08480(28)$ & $12(2)$ & $485(34)$ \\
As-doped $T_{S}=400{ }^{\circ} \mathrm{C}$ & $0.4446(3)$ & $0.08271(27)$ & $6(1)$ & $384(30)$ \\
As-doped $T_{S}=450{ }^{\circ} \mathrm{C}$ & $0.4455(3)$ & $0.08279(28)$ & $8(2)$ & $359(22)$ \\
As-doped $T_{S}=500{ }^{\circ} \mathrm{C}$ & $0.4379(3)$ & $0.08651(28)$ & $8(2)$ & $368(24)$ \\
\hline \hline
\end{tabular}

and they exhibited very similar features. The $S$ parameter first decreased with increasing positron energy, which corresponds to more positrons annihilating in the $\mathrm{ZnO}$ film (which had low $S$ parameter) as the positron energy increased. The $S$ parameter then reached a plateau, which corresponds to the $\mathrm{ZnO}$ film region. Further increasing the positron energy would increase the $S$ parameter as positrons began to annihilate in the high $S$-parameter $\mathrm{SiO}_{2}$ region. Fitting was carried out by assuming a two-layer model, i.e., the $\mathrm{ZnO}$ film and the $\mathrm{SiO}_{2}$ layer. The fitted $S$ and $W$ parameters, and the effective positron diffusion length $L_{+}$of the $\mathrm{ZnO}$ film were shown in Table I. The fitted curves were included in Fig. 5. The thicknesses of the $\mathrm{ZnO}$ film were 280 and $300 \mathrm{~nm}$ as obtained from SIMS and ellipsometry measurements, respectively. It was noticed that the fitted boundaries of the Asdoped $\mathrm{ZnO}$ film (368-485 nm), as shown in Table I, were significantly larger than the physical boundary position of $290 \mathrm{~nm}$. The deviation could be explained by an electric field existing adjacent to the $\mathrm{ZnO} / \mathrm{SiO}_{2}$ boundary.

It is well known that a linear $S$ - $W$ plot implies the existence of a single vacancy type defect in the samples. ${ }^{28,29}$ The $S-W$ plot of the present As-doped $\mathrm{ZnO}$ samples grown at different substrate temperatures did not fall into a straight line (not shown in the figure). This implied that there existed more than one type of vacancy type defect in the samples grown at different $T_{S}$. For $\mathrm{ZnO}$, it was known that $\mathrm{V}_{\mathrm{Zn}}$ related defects and their cluster would trap positrons and the positrons annihilating from these states would yield a higher value of $S$ parameter (a lower value of $W$ parameter) than the delocalized bulk state. Positron trapped in $\mathrm{V}_{\mathrm{O}}$ has low binding energy $(\sim 0.01 \mathrm{eV})$ while that for $\mathrm{V}_{\mathrm{Zn}}$ is $\sim 0.50 \mathrm{eV} .{ }^{39}$ Thus, thermal detrapping of positrons from $\mathrm{V}_{\mathrm{O}}$ is significant at RT, and positron trapping in $\mathrm{V}_{\mathrm{O}}$ is not taken into account in analyzing the PAS data obtained at RT. ${ }^{40}$

The $S$ and $W$ parameters of the As-doped films as a function of the substrate temperature $T_{S}$ were shown in Fig. 6. The $S$ and $W$ parameters were anticorrelated, showing that their evolutions were determined by positron trapping and annihilating in $\mathrm{V}_{\mathrm{Zn}}$ related defects and/or their cluster. The $S$ parameter increased (the $W$ parameter decreased) with increasing $T_{S}$ for $T_{S}<450{ }^{\circ} \mathrm{C}$. Further increasing the $T_{S}$ would result in a drop in the observed $S$ parameter (an increase in the $W$ parameter). As the measured $S$ and $W$ param-

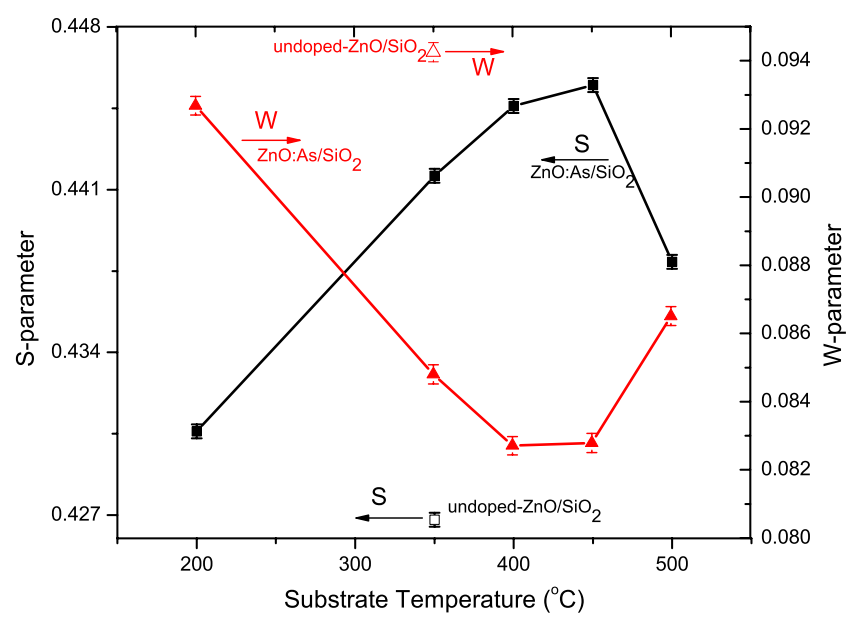

FIG. 6. (Color online) $S$ parameter (black solid square) and $W$ parameter (red solid triangle) of the RFMS grown As-doped $\mathrm{ZnO}$ films plotted against substrate temperatures. The empty red triangle and black square referred to the $W$ and $S$ parameters, respectively, of the undoped $\mathrm{ZnO}$ film grown at the substrate temperature of $350{ }^{\circ} \mathrm{C}$. All the films were grown on the $\mathrm{SiO}_{2}$ substrates.

eters are the weighted sums from different annihilating states and more than one vacancy type defects exist in the films grown at different $T_{S}$, it is difficult to make concrete interpretation on the $S$ (and $W$ ) parameter dependence on $T_{S}$. However, it would still be worth discussing the possible cause behind the $S$ and $W$ parameter observations. The observed trend of the $S$ parameter and the $p$-type conductivity as a function of the substrate temperature are in indeed good correlation. For $\mathrm{ZnO}$ :As grown on $\mathrm{SiO}_{2}$ substrate, the material changed from $n$ type to $p$ type (as shown in Fig. 2) as the substrate temperature increased to $\sim 400{ }^{\circ} \mathrm{C}$. The hole concentration then dropped with further increasing $T_{S}$. At the same time, the $S$ parameter increased (and $W$ parameter decreased) with $T_{S}$, reaching a maximum at $T_{S}=400-450{ }^{\circ} \mathrm{C}$, and then decreased (Fig. 6). Moreover, it was also observed that the undoped $\mathrm{ZnO}$ sample had an $S$ parameter significantly lower than any $\mathrm{ZnO}$ :As samples. The increase in $S$ parameter (increase in $W$ parameter) could originate from the increase of the $\mathrm{V}_{\mathrm{Zn}}$ 's open volume. In the first-principles calculation of Limpijumnong et al., ${ }^{23}$ it was found that for the shallow acceptor complex $\mathrm{As}_{\mathrm{Zn}}-2 \mathrm{~V}_{\mathrm{Zn}}$ possessing the charge state of $q=0$ or -1 , the $\mathrm{O}$ atom attaching the As atom and adjacent to the $\mathrm{V}_{\mathrm{Zn}}$ would have atomic relaxation toward the As atom. The As-O bond length would be shortened by $5 \%$ as compared to the normal $\mathrm{Zn}-\mathrm{O}$ bond. This atomic relaxation would lead to the increase in the empty volume of the $\mathrm{V}_{\mathrm{Zn}}$ and thus its characteristic $S$ parameter. For substrate temperatures lower than $\sim 400{ }^{\circ} \mathrm{C}$, the correlated increase in $S$ parameter and $p$-type conductivity against $T_{S}$ could thus be understood in terms of the increase in open volume size of the $V_{Z n}$ attached to the $A s_{Z n}-2 V_{Z n}$ shallow acceptor complex during the $A s_{Z n}-2 V_{Z n}$ formation. While $T_{S}$ further increased to $500{ }^{\circ} \mathrm{C}$, both the $S$ parameter and $p$-type conductivity decreased. The origin of this decrease was not unambiguously identified, but could be due to the thermal dissociation of the $\mathrm{As}_{\mathrm{Zn}}-2 \mathrm{~V}_{\mathrm{Zn}}$ shallow acceptor complex. 


\section{CONCLUSION}

In conclusion, As-doped $\mathrm{ZnO}$ films were fabricated by RFMS. The As atom was found to occupy the $\mathrm{Zn}$ site in the lattice. A substrate temperature of higher than $400{ }^{\circ} \mathrm{C}$ or post growth annealing was needed to achieve $p$-type $\mathrm{ZnO}$ films. The fabricated $p$-type As-doped films had $p \sim 6$ $\times 10^{17} \mathrm{~cm}^{-3}$ and $\mu_{h}=6 \mathrm{~cm}^{2} \mathrm{~V}^{-1} \mathrm{~s}^{-1}$. PL study showed that the acceptor binding energy was $\sim 150 \mathrm{meV}$. Both XPS and PL results were consistent with the model of Limpijumnong et al. ${ }^{23}$ whereby the $\mathrm{As}_{\mathrm{Zn}}-2 \mathrm{~V}_{\mathrm{Zn}}$ from the reaction between $\mathrm{As}_{\mathrm{Zn}}$ and $\mathrm{V}_{\mathrm{Zn}}$ was the shallow acceptor responsible for the $p$-type conduction in As-doped $\mathrm{ZnO}$. The results of XPS, PL, and PAS and the thermal studies lead us to suggest a comprehensive picture of the $\mathrm{As}_{\mathrm{Zn}}-2 \mathrm{~V}_{\mathrm{Zn}}$ shallow acceptor formation. At least some As-related shallow acceptor had already formed at the low substrate temperature of $200{ }^{\circ} \mathrm{C}$. However, due to defect compensation, the yielded $\mathrm{ZnO}$ film was high resistance $n$ type. Thermal process was required to activate the $p$-type conduction of the As-doped films. The thermal process activated the diffusion of the involved defects for the $\mathrm{As}_{\mathrm{Zn}}-2 \mathrm{~V}_{\mathrm{Zn}}$ shallow acceptor complex formation and probably also removed other compensating centers.

\section{ACKNOWLEDGMENTS}

This work was supported by the GRF (Grant Nos. 7037/ 06P and 7031/08P), RGC, HKSAR, and the Germany/Hong Kong Research (Grant No. G_HK026/07) awarded by RGC, HKSAR, and DAAD, Germany.

${ }^{1}$ Zinc Oxide Bulk, Thin Films and Nanostructures Processing, Properties and Applications, edited by C. Jagadish and Ss. J. Pearton (Elsevier, New York, 2006).

${ }^{2}$ Ü. Özgür, Ya. I. Alivov, C. Liu, A. Teke, M. A. Reshchikov, S. Doğan, V. Avrutin, S.-J. Cho, and H. Morkoç, J. Appl. Phys. 98, 041301 (2005).

${ }^{3}$ S. J. Pearton, D. P. Norton, K. Ip, Y. W. Heo, and T. Steiner, J. Vac. Sci. Technol. B 22, 932 (2004).

${ }^{4}$ D. C. Look, Mater. Sci. Eng., B 80, 383 (2001).

${ }^{5}$ S. B. Zhang, S.-H. Wei, and A. Zunger, Phys. Rev. B 63, 075205 (2001).

${ }^{6}$ K. Minegishi, Y. Koiwai, and K. Kikuchi, Jpn. J. Appl. Phys., Part 2 36, L1453 (1997).

${ }^{7}$ M. Joseph, H. Tabata, H. Saeki, K. Ueda, and T. Kawai, Physica B 302, 140 (2001).

${ }^{8}$ D. C. Look, D. C. Reynolds, C. W. Litton, R. L. Jones, D. E. Eason, and G. Cantwell, Appl. Phys. Lett. 81, 1830 (2002).

${ }^{9}$ Y. R. Ryu, T. S. Lee, and H. W. White, Appl. Phys. Lett. 83, 87 (2003).

${ }^{10}$ K. K. Kim, H. S. Kim, D. K. Hwang, J. H. Lim, and S. J. Park, Appl. Phys. Lett. 83, 63 (2003).

${ }^{11}$ X. Li, Y. Yan, T. A. Gessert, C. L. Perkins, D. Young, C. DeHart, M. Young, and T. J. Coutts, J. Vac. Sci. Technol. A 21, 1342 (2003).

${ }^{12}$ Y. W. Heo, Y. W. Kwon, Y. Li, S. J. Pearton, and D. P. Norton, Appl. Phys. Lett. 84, 3474 (2004).
${ }^{13}$ C. C. Lin, S. Y. Chen, S. Y. Cheng, and H. Y. Lee, Appl. Phys. Lett. 84, 5040 (2004).

${ }^{14}$ D. C. Look, G. M. Renlund, R. H. Burgener, and J. R. Sizelove, Appl. Phys. Lett. 85, 5269 (2004).

${ }^{15}$ A. Tsukazaki, A. Ohtomo, M. Ohtani, T. Makino, M. Sumiya, K. Ohtani, S. F. Chichibu, S. Fuke, Y. Segwa, H. Ohno, H. Koinuma, and M. Kawasaki, Nature Mater. 4, 42 (2005).

${ }^{16}$ G. Braunstein, A. Muraviev, H. Saxena, V. Richter, and R. Kalish, Appl. Phys. Lett. 87, 192103 (2005).

${ }^{17}$ V. Vaithianathan, B. T. Lee, and S. S. Kim, Appl. Phys. Lett. 86, 062101 (2005).

${ }^{18}$ H. S. Kang, G. H. Kim, D. L. Kim, H. W. Chang, B. D. Ahn, and S. Y. Lee, Appl. Phys. Lett. 89, 181103 (2006).

${ }^{19}$ Q. L. Gu, C. C. Ling, G. Brauer, W. Anwand, W. Skorupa, Y. F. Hsu, A. B. Djurišić, C. Y. Zhu, S. Fung, and L. W. Lu, Appl. Phys. Lett. 92, 222109 (2008).

${ }^{20}$ M. Joseph, H. Tabata, and T. Kawai, Jpn. J. Appl. Phys., Part 2 38, L1205 (1999).

${ }^{21}$ J. M. Bian, X. M. Li, X. D. Gao, W. D. Yu, and L. D. Chen, Appl. Phys. Lett. 84, 541 (2004).

${ }^{22}$ J. G. Lu, Z. Z. Ye, F. Zhuge, Y. J. Zeng, B. H. Zhao, and L. P. Zhu, Appl. Phys. Lett. 85, 3134 (2004).

${ }^{23}$ S. Limpijumnong, S. B. Zhang, S.-H. Wei, and C. H. Park, Phys. Rev. Lett. 92, 155504 (2004).

${ }^{24}$ U. Wahl, E. Rita, J. G. Correia, A. C. Marques, E. Alves, J. C. Soares, and ISOLDE Collaboration, Phys. Rev. Lett. 95, 215503 (2005).

${ }^{25}$ S. Limpijumnong, M. F. Smith, and S. B. Zhang, Appl. Phys. Lett. 89, 222113 (2006)

${ }^{26}$ V. Vaithianathan, B.-T. Lee, C.-H. Chang, K. Asokan, and S. S. Kim, Appl. Phys. Lett. 88, 112103 (2006)

${ }^{27}$ V. Vaithianathan, S. S. Kim, and K. Asokan, Appl. Phys. Lett. 92, 236101 (2008).

${ }^{28}$ Positron Annihilation in Semiconductors Defect Studies, edited by R. Krause-Rehberg and H. S. Leipner (Springer, Berlin, 1999).

${ }^{29}$ Positron Beams and their Applications, edited by P. Coleman (World Scientific, Singapore, 2000)

${ }^{30}$ A. van Veen, H. Schut, J. de Vries, R. A. Hakvoort, and M. R. Ijpma, AIP Conf. Proc. 218, 171 (1991)

${ }^{31}$ L. W. Lu, C. K. So, C. Y. Zhu, Q. L. Guo, C. J. Li, S. Fung, G. Brauer, W. Anwand, W. Skorupa, and C. C. Ling, Semicond. Sci. Technol. 23, 095028 (2008).

${ }^{32}$ C. Y. Zhu, C. C. Ling, G. Brauer, W. Anwand, and W. Skorupa, Microelectron. J. 40, 286 (2009).

${ }^{33}$ G. Hollinger, R. Skheyta-Kabbani, and M. Gendry, Phys. Rev. B 49, 11159 (1994)

${ }^{34}$ Handbook of X-ray Photoelectron Spectroscopy, edited by G. E. Muilenberg (Perkin Elmer, Eden Prairie, MN, 1979).

${ }^{35}$ J. Petersen, C. Brimont, M. Gallart, O. Crégut, G. Schmerber, P. Gillot, B. Hönerlage, C. Ulhaq-Bouillet, J. L. Rehspringer, C. Leuvrey, S. Colis, H. Aubriet, C. Becker, D. Ruch, A. Slaoui, and A. Dinia, J. Appl. Phys. 104, 113539 (2008).

${ }^{36}$ Y. Zhong, A. B. Djurišić, Y. F. Hsu, K. S. Wong, G. Brauer, C. C. Ling, and W. K. Chan, J. Phys. Chem. C 112, 16286 (2008).

${ }^{37}$ D. C. Look and B. Clalin, Phys. Status Solidi B 241, 624 (2004).

${ }^{38}$ D.-K. Hwang, H.-S. Kim, J.-H. Lim, J.-Y. Oh, K.-K. Kim, D. C. Look, and Y. S. Park, Appl. Phys. Lett. 86, 151917 (2005).

${ }^{39}$ G. Brauer, W. Anwand, W. Skorupa, J. Kuriplach, O. Melikhova, and C. Moisson, Phys. Rev. B 74, 045208 (2006).

${ }^{40}$ Z. Q. Chen, K. Betsuyaku, and A. Kawasuso, Phys. Rev. B 77, 113204 (2008). 